\title{
Influência do inóculo na co-digestão anaeróbia de resíduos alimentares e grama
}

O inóculo configura-se como importante parâmetro no desempenho da digestão anaeróbia, uma vez que fornece a comunidade microbiana necessária ao início do processo de conversão e estabilização da matéria orgânica, contribuindo para o equilíbrio de outros parâmetros essenciais ao funcionamento da digestão, a exemplo do pH. Dado as vantagens da utilização de um sistema com alto teor de sólidos e a lacuna existente na literatura sobre a relação substrato/inóculo para tais sistemas, a presente pesquisa teve como objetivo verificar a influência da quantidade de inóculo na digestão anaeróbia de resíduos alimentares e grama com alto teor de sólidos. Para tal, quantificou-se a produção acumulada de biogás, redução de sólidos voláteis e pH da massa digerida. A influência do teor de inóculo foi verificada por meio da variação de 100 para $200 \mathrm{ml}$, mantidas as mesmas proporções de grama e resíduos alimentares. 0 ensaio de digestão foi conduzido tomando como base as normas alemãs VDI 4630 e DIN 38414 (S8), e os resultados analisados através de teste de hipótese para duas amostras. Verificou-se uma redução de sólidos voláteis de $14 \%$ a mais para a triplicata com $200 \mathrm{ml}$, bem como uma produção de biogás e pH, cerca de 3,4 e 2,6 vezes maior, se comparado à de $100 \mathrm{ml}$. Com $5 \%$ de significância concluiu-se que o aumento da quantidade de inóculo contribui para o aumento médio da geração de biogás. Infere-se, neste contexto, que o volume de $100 \mathrm{ml}$ não foi eficiente para fornecer a quantidade de microrganismos suficientes para superar a produção de ácidos orgânicos voláteis, que ocorre em maior quantidade após o primeiro dia de incubação. Deste modo, depreende-se que a quantidade de inóculo possui um papel relevante na geração de biogás, que vai além do controle do $\mathrm{pH}$.

\section{Inoculum's influence on anaerobic co-digestion of food waste and grass}

The inoculum is an important parameter in the performance of anaerobic digestion, since it provides the microbial community necessary for the beginning of the process of conversion and stabilization of organic matter, contributing to the balance of other parameters essential to the functioning of digestion, such as $\mathrm{pH}$ Given the advantages of using a high solids system and the gap in the literature on the ratio substrate / inoculum for such systems, this research aimed to verify the influence of the amount of inoculum on anaerobic co-digestion of food waste and grass with high solids content. For this, the accumulated biogas production reduction of volatile solids and $\mathrm{pH}$ of the digested mass were quantified. The influence of inoculum content was verified by varying from 100 to $200 \mathrm{ml}$, maintaining the same proportions of grass and food waste. The digestion test was conducted based on German VDI 4630 and DIN 38414 (S8) standards, and the results analyzed by hypothesis testing for two samples. Volatile solids were reduced by $14 \%$ more for the $200 \mathrm{ml}$ triplicate, as well as about 3.6 and 2.6 times higher biogas production and $\mathrm{pH}$ compared to $100 \mathrm{ml}$. With $5 \%$ significance it was concluded that the increase in the amount of inoculum contributes to the average increase of biogas generation. It's possible to infer, therefore, that the volume of $100 \mathrm{ml}$ was not efficient to provide sufficient microorganisms to overcome the production of volatile organic acids, which occurs in greater quantity after the first day of incubation. Thus, it appears that the amount of inoculum plays a relevant role in biogas generation, which goes beyond $\mathrm{pH}$ control.

Keywords: Inoculum; Anaerobic Co-Digestion; Biogas; Food Waste; Grass.

Topic: Engenharia Sanitária

Reviewed anonymously in the process of blind peer.

Fernanda de Marco de Souza (iD)

Universidade de São Paulo, Brasil

http://lattes.cnpq.br/5342355090074447

http://orcid.org/0000-0002-9263-8735

fernanda.marco.souza@usp.br

Ednilson Viana

Universidade de São Paulo, Brasil

http://lattes.cnpq.br/7928208403989434

http://orcid.org/0000-0002-8483-4082

ednilson.viana@gmail.com

Joyce Meneses da Silva Jaeger (iD

Universidade de São Paulo, Brasil

http://lattes.cnpq.br/5300304875725665

http://orcid.org/0000-0003-4754-7751

joycejaeger11@gmail.com

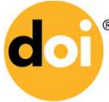

DOI: 10.6008/CBPC2179-6858.2020.001.0014
Received: 07/12/2019

Approved: 09/01/2020

\author{
Giovano Candiani (it) \\ Universidade de São Paulo, Brasil \\ http://lattes.cnpq.br/9950995765229751 \\ http://orcid.org/0000-0001-9896-4390 \\ giovanocandiani@gmail.com \\ André Felipe Simões \\ Universidade de São Paulo, Brasil \\ http://lattes.cnpq.br/1503283535579534 \\ http://orcid.org/0000-0002-4108-9596 \\ afsimoes@usp.br \\ Homero Fonseca Filho \\ Universidade de São Paulo, Brasil \\ http://lattes.cnpq.br/8291933997449674 \\ http://orcid.org/0000-0003-4737-9938 \\ homeroff@usp.br
}

\section{Referencing this:}

SOUZA, F. M.; VIANA, E.; JAEGER, J. M. S.; CANDIANI, G.; SIMÕES, A. F.; FONSECA FILHO, H.. Influência do inóculo na co-digestão anaeróbia de resíduos alimentares e grama. Revista Ibero Americana de Ciências Ambientais, v.11, n.1, p.146-156, 2020. DOI:

http://doi.org/10.6008/CBPC2179-6858.2020.001.0014 


\section{INTRODUÇÃO}

A digestão anaeróbia é um processo de conversão biológica da matéria orgânica em biogás (uma fonte de energia, composta principalmente por metano e dióxido de carbono) e massa digerida, o digerido. Uma comunidade de microrganismos é responsável por catalisar as reações na ausência de oxigênio e os compostos são convertidos nos subprodutos citados, assim como em nova biomassa microbiana (ANGELIDAKI et al., 2004). Tal processo exige a presença de diferentes microrganismos, daí a importância da utilização de um inóculo.

O inóculo fornece uma comunidade microbiana que é habilitada para digerir a matéria orgânica (HOLLIGER et al., 2016), atuando, portanto, na aceleração do processo inicial de biodegradação das moléculas orgânicas. A origem do inóculo influenciará na existência de diferentes populações bacterianas, na atividade inicial dos microrganismos e também nas diferentes adaptações destes ao substrato. Frequentemente, tem-se a utilização de lodos de estações de tratamento de águas residuárias, digeridos de plantas anaeróbias, esterco animal e resíduos biológicos (OHEMENG-NTIAMOAH et al., 2019). A razão substrato por inóculo é um importante fator, uma vez que a depender da quantidade, este pode ser tóxico ou impedir a indução enzimática, quando a proporção não é adequada (ELBESHBISHY et al., 2012).

A complexidade da interação entre os substratos e inóculo aumenta conforme o conteúdo sólido a ser digerido. Dentro deste contexto, um ponto importante é evitar o acúmulo de ácidos graxos voláteis, de maneira que a quantidade de inóculo deve ser suficiente para superar a acidificação inicial. Deste modo, a relação de substrato/inóculo é um fator relevante para sistemas com alto teor de sólidos (NEVES et al., 2004). Ressalta-se ainda que a relação inóculo e substrato possui efeitos somente sobre a cinética da reação (no qual a fase de latência para o início do processo é menor para maiores proporções de inóculo), e não sobre o rendimento de biometano, que depende exclusivamente do teor de sólidos voláteis (LESTEUR et al., 2010).

No tocante ao teor de sólidos, estes são divididos em sólidos voláteis e fixos, que correspondem, respectivamente à matéria orgânica e inorgânica presente nos substratos. Os voláteis são os sólidos que servem como referência para se predizer sobre a eficiência da digestão anaeróbia, uma vez que correspondem à porção passível de ser biodegradada pelos microrganismos e convertida em biogás. De acordo com o teor de sólidos presentes nos digestores, a digestão pode ser classificada em: úmida, quando o teor de sólidos totais é menor que $15 \%$, e seca (ou com alto teor de sólidos), quando o teor de sólidos totais é maior que 15\% (YANG et al., 2015; ZHU et al., 2014).

Como características positivas, um sistema com alto teor de sólidos necessita de um menor volume de reator, menor consumo e demanda de energia para o aquecimento do sistema, assim como o digerido produzido com esta faixa de teor de sólidos é mais fácil de ser manuseado, devido a menor quantidade de água. Por fim, mais de $60 \%$ dos digestores anaeróbios construídos na Europa, recentemente, adotam esse tipo de faixa de operação (BROWN et al., 2013; ZHU et al., 2014; YANG et al., 2015).

Deste modo, este artigo tem como objetivo apresentar a influência do inóculo na co-digestão anaeróbia de resíduos alimentares e grama em um sistema com alto teor de sólidos. Para isso, quantificou- 
se a produção acumulada de biogás, redução de sólidos voláteis e pH da massa digerida. Esta pesquisa visa também acrescentar dados à literatura sobre a relação substrato inóculo para sistemas com alto teor de sólidos, visto que se tem, de forma preponderante, informações e resultados para sistemas com baixo teor de sólidos, com o uso de elevada quantidade de inóculo (ELBESHBISHY et al., 2012; KOCH et al., 2017; BRAGUGLIA et al., 2018; Ll et al., 2019; OHEMENG-NTIAMOAH et al., 2019).

\section{MATERIAIS E MÉTODOS}

Para atingir o objetivo proposto, realizou-se um ensaio para verificar a produção de biogás baseado nas normas alemãs VDI 4630 e DIN 38414 (S8).

\section{Aparatos e reagentes experimentais}

Dentre as opções para medição de biogás previstas nas normas supracitadas, optou-se pela leitura em tubos eudiômetros de $500 \mathrm{ml}$, com graduação de $1 \mathrm{ml}$, da marca FGG e calibração da Rede Brasileira de Calibração (RBC), acoplados a frascos reatores de $1 \mathrm{~L}$, em vidro (Figura 1), vedados com graxa a base de Silicone Molykote HVG.

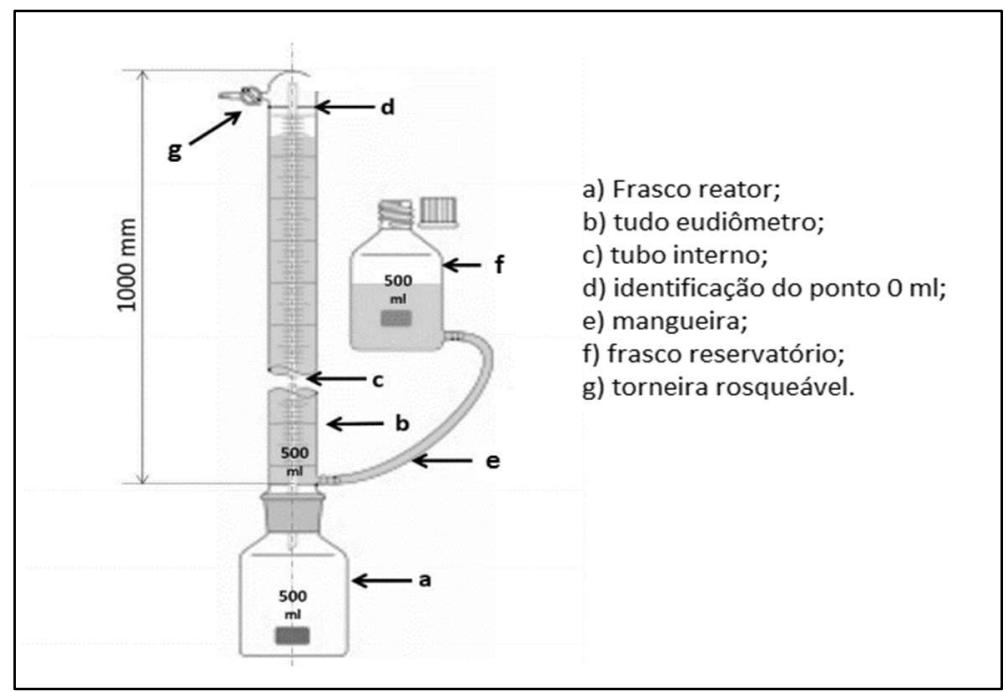

Figura 1: Esquema do conjunto eudiômetro utilizado nos experimentos. Fonte: adaptado de Lima (2016).

Neste sistema, a quantidade de biogás gerada é obtida através da visualização do deslocamento do líquido selante contido no eudiômetro graduado. A leitura do biogás deve ser feita igualando o menisco do líquido selante do tubo eudiômetro com o menisco do frasco reservatório, para que apenas a pressão atmosférica esteja incidindo na coluna de biogás. Caso a medição seja realizada a partir do nível 0 do eudiômetro, deve-se ajustar uma equação de reta para a produção de biogás e aplicar nos valores lidos a partir do líquido deslocado. Com vistas a facilitar o manuseio das vidrarias, optou-se por ajustar a equação, através do método de regressão linear $\left(y=1,2292 x-0,4171\right.$, com $R^{2}$ de 0,989$)$.

\section{Líquido Selante}

No que concerne à composição do líquido selante, este consiste em uma solução ácida que evita a 
solubilização do dióxido de carbono presente no biogás. Para tal, a solução foi preparada a partir de $200 \mathrm{~g}$ de sulfato de sódio decahidratado $\left(\mathrm{Na}_{2} \mathrm{SO}_{4} * 10 \mathrm{H}_{2} \mathrm{O}\right)$ e $30 \mathrm{ml}$ de ácido sulfúrico $\left(\mathrm{H}_{2} \mathrm{SO}_{4}\right.$, concentração $98 \%$ e densidade $1,84 \mathrm{~g} / \mathrm{cm}^{3}$ ), para cada $1000 \mathrm{ml}$ de água destilada.

\section{Correção do biogás}

Com o intuito de eliminar os erros sistemáticos relacionados à quantificação da produção de biogás, os valores observados foram convertidos às condições normais de temperatura e pressão ( $273 \mathrm{~K}$ e 1013,25 mbar), conforme Equação 1 (VD1 4630).

$$
V 0=V \cdot \frac{(P L-P W) \cdot T 0}{P 0 . T}
$$

Onde,

$V_{0}=$ volume de biogás em condições normais; $V$ = volume registrado no eudiômetro;

$P_{L}=$ pressão atmosférica no momento do registro (mbar); $\mathrm{Pw}_{\mathrm{w}}=$ pressão do vapor d'água (mbar); $\mathrm{T}_{0}=$ temperatura normal $(273 \mathrm{~K})$; $P_{0}=$ pressão normal $(1013,15$ mbar $)$; $\mathrm{T}=$ temperatura $(\mathrm{K})$.

Tal correção é importante, pois o biogás é compressível, e, portanto, dependente da temperatura e pressão do ambiente, que podem superestimar os valores visualizados. Além da correção às condições normais, é necessário também levar em consideração a pressão de vapor d'água (que corresponde à pressão exercida pelas moléculas de água gasosa contidas no gás). Tal fator é relevante, considerando que o biogás esteja saturado em vapor d'água. Com vista a uma maior precisão tal efeito deve ser minimizado, uma vez que o teor de água pode maximizar os valores de produção de biogás de 2 a $8 \%$. Para tal, a equação de Antoine (Equação 2) foi utilizada (STRÖMBERG et al., 2014).

$$
P W=10^{8,1962}\left(\frac{1730,63}{T-39,724}\right)
$$

O ensaio experimental utilizado teve duração de 26 dias para garantir que a produção de biogás diária

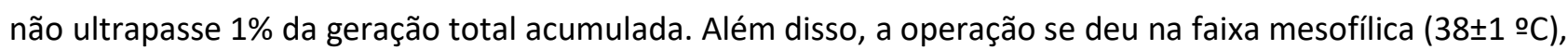
no qual os reatores de vidro foram mantidos em banho maria com aquecedores de água inteligente, embutidos de sensor interno e termômetro programado.

\section{Teste de sólidos}

Para aferição da quantidade de sólidos totais e voláteis presentes nos substratos (resíduos alimentares e grama) e massa digerida, adotou-se o método padrão recomendando no Standard Methods for the Examination of Water and Wastewater (APHA, 2012). Tal método estabelece que os sólidos totais são obtidos após secagem da amostra dos substratos e digerido em estufa a 105 드, até estabilização do peso. Após retirada da estufa, os valores pesados correspondem a quantidade de sólidos totais. Tais sólidos se dividem em sólidos fixos e voláteis. Para mensurar o teor de sólidos voláteis, levou-se as amostras para o

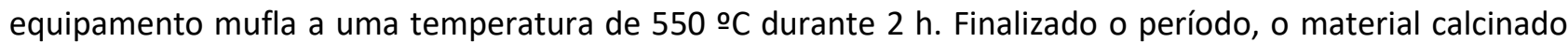
remanescente no cadinho de porcelana equivale aos sólidos fixos (não volatizados) e a quantia dos sólidos 
voláteis é obtida pela subtração dos sólidos totais pelos fixos.

\section{Proporções de Inóculo e Substrato}

Utilizou-se como inóculo, a fim de acelerar o início das reações, o lodo de um digestor anaeróbio residencial alimentando com restos alimentares, que faz parte de um projeto chamado 'Instituto Favela da Paz' e está em operação desde 2009. Tal inóculo é estabilizado e adequado para o tipo de substrato escolhido, o que implica em uma maior velocidade de decomposição (HOLLIGER et al., 2016; KOCH et al., 2017).

Para testes de potencial de biometano, a razão entre inóculo e substrato, de acordo com a VDI 4630, é estabelecida em 2:1 com base em sólidos voláteis (ou seja, a razão entre a quantidade de SV do substrato por inóculo deve ser de 0,5$)$ Entretanto, com vistas a cumprir o objetivo proposto por este trabalho, optouse por uma razão maior, que será descrita a seguir.

As proporções de resíduos alimentares e grama adotadas foram baseadas em um uma pesquisa de Chen et al., 2014, que verificaram que a produção ótima de biogás foi alcançada na proporção de 40:60 em termos de sólidos voláteis (SV), de resíduos alimentares para resíduos verdes. Cada proporção foi repetida três vezes (em triplicata, com o intuito de se retirar a média dos valores observados e calcular o desvio padrão), variando-se apenas a quantidade de inóculo (Figura 2). Desta maneira, as quantidades iniciais utilizadas no ensaio estão descritas na Tabela 1.

Tabela 1: Delineamento do ensaio experimental.

\begin{tabular}{|l|l|l|}
\hline \multirow{2}{*}{ Tipo de resíduo } & Proporções & Triplicata B \\
\cline { 2 - 3 } & Triplicata A & $75 \mathrm{~g}$ \\
\hline Resíduos alimentares & $75 \mathrm{~g}$ & $45 \mathrm{~g}$ \\
\hline Grama & $45 \mathrm{~g}$ & $200 \mathrm{ml}$ \\
\hline Inóculo & $100 \mathrm{ml}$ & \\
\hline
\end{tabular}

Tais medidas foram adotadas, uma vez que, após a realização de teste de sólidos, verificou-se que os resíduos alimentares (com predomínio de legumes e frutas) possuíam 9,76\% $\pm 0,03$ de SV e a grama 23,98\% $\pm 0,74$ (Tabela 2). Com relação à quantidade de inóculo, tais volumes foram aplicados de forma exploratória, com vista a verificar a influência na geração, com um sistema de alto teor de sólidos (acima de 15\%).

Tabela 2: Valores iniciais de sólidos presentes nos substratos e inóculo.

\begin{tabular}{|l|l|l|l|l|}
\hline Substrato & Sólidos totais (ST) & Sólidos Fixos (SF) & Sólidos Voláteis (SV) & SV/ST \\
\hline Resíduo alimentar & $10,79 \% \pm 0,01$ & $1,03 \% \pm 0,03$ & $9,76 \% \pm 0,03$ & $90,42 \% \pm 0,24$ \\
\hline Grama & $27,08 \% \pm 0,71$ & $3,1 \% \pm 0,11$ & $23,98 \% \pm 0,74$ & $88,54 \% \pm 0,54$ \\
\hline Inóculo & $0,33 \% \pm 0,00$ & $0,26 \% \pm 0,01$ & $0,07 \% \pm 0,01$ & $20,42 \% \pm 2,88$ \\
\hline
\end{tabular}

Portanto, a razão de $\mathrm{SV}_{\text {substrato/ }} \mathrm{SV}_{\text {inóculo }}$ empregada neste estudo foi de 258,7 para a triplicata A e 129,32 para a B, visto que a mistura (resíduos alimentar e grama) possuía em termos absolutos 18,11 g de SV e o inóculo 0,07 g para triplicata A e 0,14 para B - tomando como base o fator de conversão verificado de que $1 \mathrm{ml}$ de inóculo é aproximadamente $1 \mathrm{~g}$.

O inóculo utilizado foi incubado sem substrato por 5 dias para que o material biodegradável existente ainda fosse consumido (gerando a quantidade de gás devida a ele com o objetivo de esgotar os resíduos biodegradáveis ainda presentes) não influenciando, portanto, nos resultados de geração de biogás 
proveniente da digestão dos substratos (ANGELIDAKI et al., 2009; ELBESHBISHY; NAKHLA; HAFEZ, 2012). Por incubado entende-se que foi colocado às condições de início do ensaio, mantido à $38^{\circ} \mathrm{C}$ nos reatores de $1 \mathrm{~L}$. Tal procedimento também é descrito pela norma alemã supracitada.

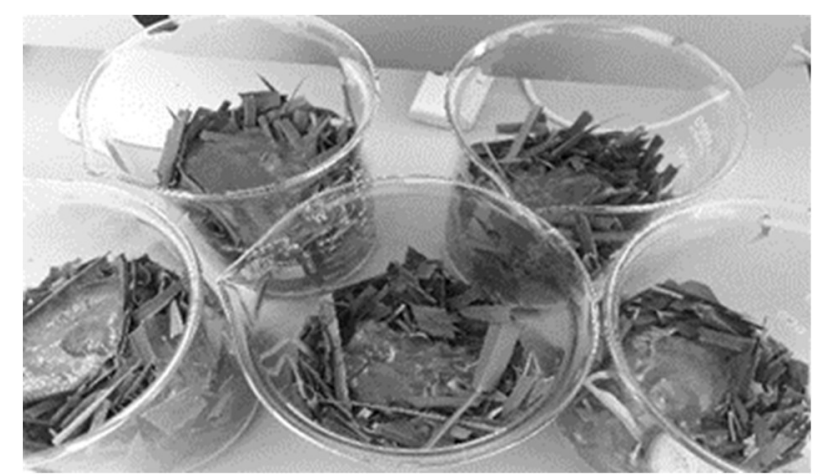

Figura 2: Imagem mostrando a montagem do experimento com distribuição das proporções de grama e resíduos.

\section{Análise dos dados}

Os dados da geração de biogás foram analisados estatisticamente por teste de hipótese de diferença entre médias, no qual se adotou o teste T para duas amostras (REIS, 2019), no dia em que se teve maior desvio padrão verificado, no qual:

$$
\begin{gathered}
\mu_{1}: \text { média de } 100 \mathrm{ml} \\
\mu_{2}: \text { média de } 200 \mathrm{ml} \\
\text { Diferença: } \mu_{1}-\mu_{2}
\end{gathered}
$$

$$
\begin{array}{rr}
\text { Hipótese nula } & H_{0}: \mu_{1}-\mu_{2}=0 \\
\text { Hipótese alternativa } & H_{1}: \mu_{1}-\mu_{2}<0
\end{array}
$$

Com isso, buscou-se verificar se o aumento de inóculo causou um aumento médio na produção de biogás. Por fim, não se assumiu igualdade de variâncias para a análise e adotou-se $5 \%$ de significância. Para análise da produção de biogás, a média foi aplicada para os valores obtidos diariamente nas triplicatas e o desvio padrão calculado. Além disso, os dados do pH também foram analisados pelo teste para duas amostras, no qual buscou-se testar se a diferença entre as médias era significativa (também com $5 \%$ de significância), assumindo igualdade de variâncias, a partir de:

$$
\begin{gathered}
\mu_{1}: \text { média de } \mathrm{pH}(100 \mathrm{ml}) \\
\mu_{2}: \text { média de } \mathrm{pH}(200 \mathrm{ml}) \\
\text { Diferença: } \mu_{1}-\mu_{2}
\end{gathered}
$$

\section{RESULTADOS}

Finalizados os 26 dias, os dados de geração de biogás, pH e teor de sólidos na massa digerida foram verificados para as duas triplicatas e descritos a seguir.

\section{Reduções de sólidos voláteis}

As características iniciais de sólidos totais e voláteis foram usadas como base para se calcular a 
redução na quantidade de sólidos voláteis, matéria orgânica que de fato pode ser biodegradada pelas bactérias (YANG et al., 2015). Partindo-se das proporções adotadas, inicialmente o sistema possuía 17\% de sólidos totais, e deste, 15,1\% eram voláteis. Ao final da digestão, as massas digeridas apresentaram menores valores de sólidos voláteis, ou seja, 52,61\% de redução para a triplicata A e 66,34\% para a triplicata B (Tabela 3).

Tabela 3: Reduções nas quantidades de sólidos totais (ST) e voláteis (SV) em termos de g/g de amostra.

\begin{tabular}{|l|l|l|l|l|l|l|}
\hline \multirow{2}{*}{ Triplicata } & \multicolumn{3}{|l|}{ Sólidos totais } & \multicolumn{2}{l|}{ Sólidos voláteis } \\
\cline { 2 - 7 } & Inicial & Final & Redução (\%) & Inicial & Final & Redução (\%) \\
\hline A (100 ml) & 0,172 & 0,102 & $40,70 \%$ & 0,152 & 0,072 & $52,61 \%$ \\
\hline B (200 ml) & 0,174 & 0,059 & $66,21 \%$ & 0,152 & 0,051 & $66,34 \%$ \\
\hline
\end{tabular}

Verifica-se que a triplicata com maior quantidade de inóculo foi a que apresentou melhor desempenho na redução de sólidos voláteis (cerca de 13,7\% a mais, se comparada à $100 \mathrm{ml}$ ). Os valores da redução na quantia de sólidos voláteis situam-se próximo à faixa de eficiência de remoção orgânica (25 a $50 \%$ em termos de SV) para digestores operados em temperaturas mesofílicas com um tempo de detenção hidráulica entre 10 e 20 dias (DOHÁNYOS et al., 2001, citado por LEITE et al., 2015).

\section{Geração acumulada de biogás}

Diretamente relacionado à eficiência de redução na quantidade de sólidos voláteis (que são convertidos em biogás), a maior produção média de biogás (em Nml) para a triplicata com $200 \mathrm{ml}$ foi 3,4 vezes maior se comparada à de $100 \mathrm{ml}$, conforme mostra a Figura 3.

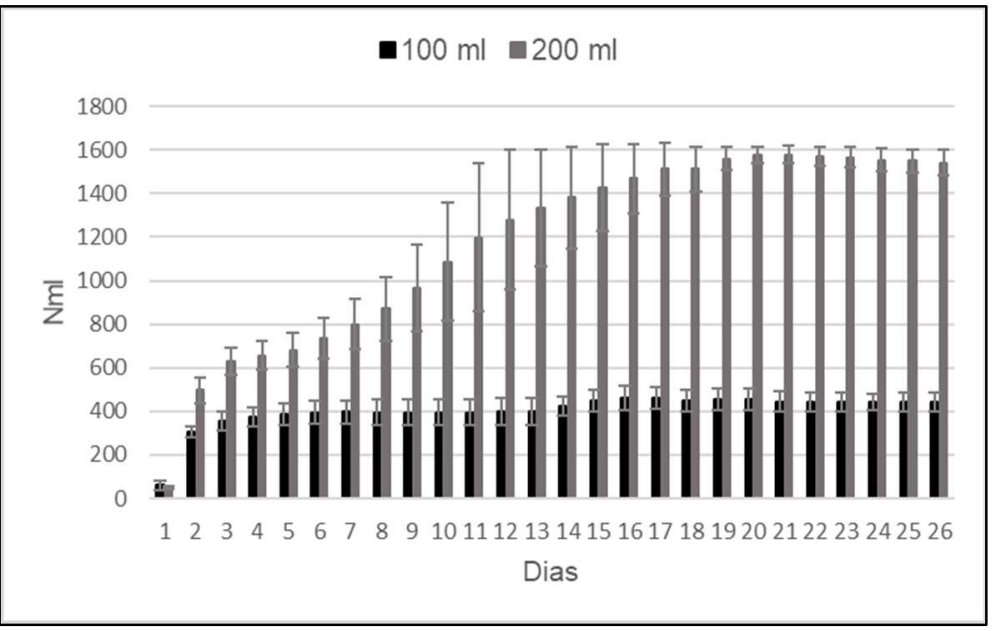

Figura 3: Produção acumulada de biogás para as triplicatas $A$ e $B$, os valores médios $(n=3)$ são plotados e as barras de erro indicam o desvio padrão.

Ainda de acordo com a Figura 3, observa-se que a geração de biogás para $100 \mathrm{ml}$ estabilizou logo nos primeiros dias de ensaio e para a de $200 \mathrm{ml}$, próximo ao dia 20. A partir das análises estatísticas, o teste $t$ de hipótese para o dia 11 (no qual se obteve o maior desvio padrão verificado, de $340 \mathrm{ml}$ para a triplicata B) apresentou um valor $p$ de $0,028(>0,05)$ de maneira que, com $5 \%$ de significância, conclui-se que o aumento da quantidade de inóculo contribuiu para o aumento médio da geração de biogás (Tabela 4). 
Tabela 4: Resultado do teste de hipótese para a geração de biogás.

\begin{tabular}{|l|l|l|}
\hline Valor-T & GL & Valor-p \\
\hline$-4,03$ & 2 & 0,028 \\
\hline
\end{tabular}

\section{pH da massa digerida}

Finalizado o período do ensaio, ao se aferir o $\mathrm{pH}$ da massa digerida para os dois tratamentos, verificou-se que a triplicata com $100 \mathrm{ml}$ apresentou um valor 2,6 vezes menor que a triplicata com maior conteúdo do agente facilitador do início da digestão.

Tabela 5: Valores de pH antes e após a digestão.

\begin{tabular}{|l|l|l|}
\hline \multirow{2}{*}{ Triplicata } & pH & \multicolumn{2}{|l|}{} \\
\cline { 2 - 3 } & Inicial & Final \\
\hline A (100 ml) & $5,84 \pm 0,24$ & $2,03 \pm 0,19$ \\
\hline B (200 ml) & $6,58 \pm 0,16$ & $5,29 \pm 0,13$ \\
\hline
\end{tabular}

Ainda, com base no teste t para determinar se as médias diferem significativamente entre as duas triplicatas, obteve-se um p valor de $0,000(<0,05)$ indicando que, com $5 \%$ de significância as médias são diferentes (Tabela 6).

Tabela 6: Resultado do teste de hipótese para o $\mathrm{pH}$.

\begin{tabular}{|l|l|l|}
\hline Valor-T & GL & Valor-p \\
\hline$-24,53$ & 3 & 0,000 \\
\hline
\end{tabular}

\section{DISCUSSÃO}

\section{Curvas de geração de biogás}

Ao se analisar o comportamento das curvas de geração de biogás, com base no que as normas alemãs supracitadas na metodologia descrevem (Figura 4), verifica-se que para a maior produção observada, temse que está se assemelha visualmente à 'produção de biogás atrasada no tempo'. Tal curva ocorre, em muitos casos, devido à ocorrência de altas concentrações de substratos formados a partir de uma composição heterogênea (LIMA, 2016; WALTER et al., 2016), que está presente na pesquisa em questão, no qual se teve a co-digestão de resíduos alimentares e grama.

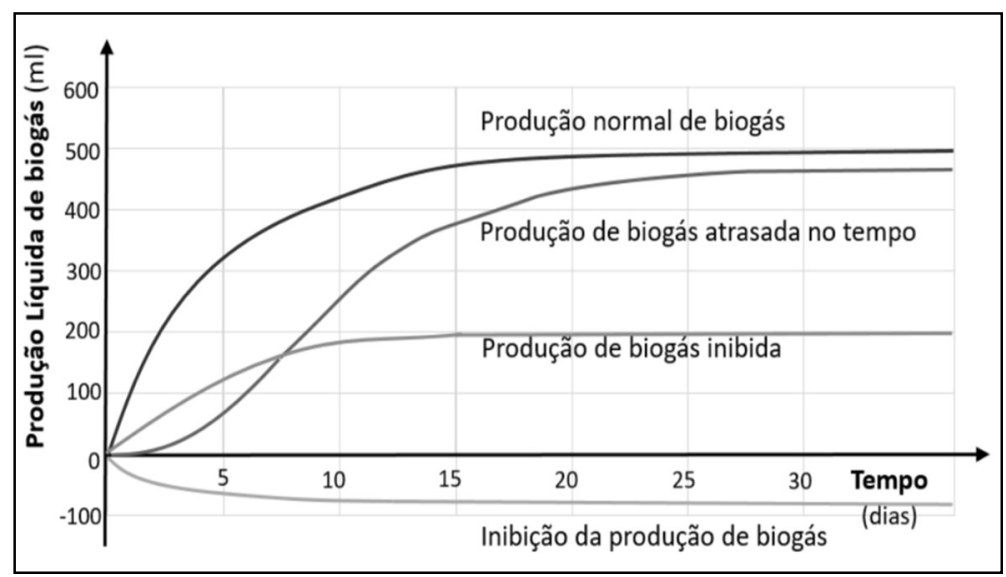

Figura 4: Exemplos de curvas típicas de produção de biogás. Fonte: adaptado de DIN 38414-8 (1985) e VDI 4630(2006) por Lima (2016).

Verifica-se este comportamento, pois a comunidade microbiana consome mais facilmente os 
substratos mais biodegradáveis e somente após consumi-los parte para outros elementos do substrato (WALTER et al., 2016). Dentro deste contexto, tem-se que os resíduos alimentares apresentam maior digestibilidade se comparados aos resíduos lignocelulósicos - como a grama (CHEN et al., 2014).

Por sua vez, a produção média observada para a triplicata de $100 \mathrm{ml}$ de inóculo é semelhante à curva de produção de biogás inibida. Esta inibição pode estar correlacionada com o acúmulo de ácidos graxos ao longo da digestão, que diminuem o pH e inibem a metanogênese, fase na qual se tem a geração de metano (GONÇALVES, 2012; BROWN et al., 2013). Tal acúmulo possui indícios no valor de pH verificado na massa digerida, que será descrito na próxima seção.

Por fim, com vista à comparação com o estudo que serviu como referência para o cálculo das proporções utilizadas, quando verificada a produção acumulada de biogás por grama de sólido volátil ( $\mathrm{Nml} /$ g.SV) se obteve aproximadamente $74 \mathrm{Nml} / \mathrm{g} . S V$ para a maior geração (vide Figura 5), o que é 5,2 vezes menor do que foi verificado por Chen et al. (2014). Entretanto, é válido ressaltar que estes utilizaram uma maior proporção de inóculo, com razão de substrato por inóculo em termos de SV igual a 1.

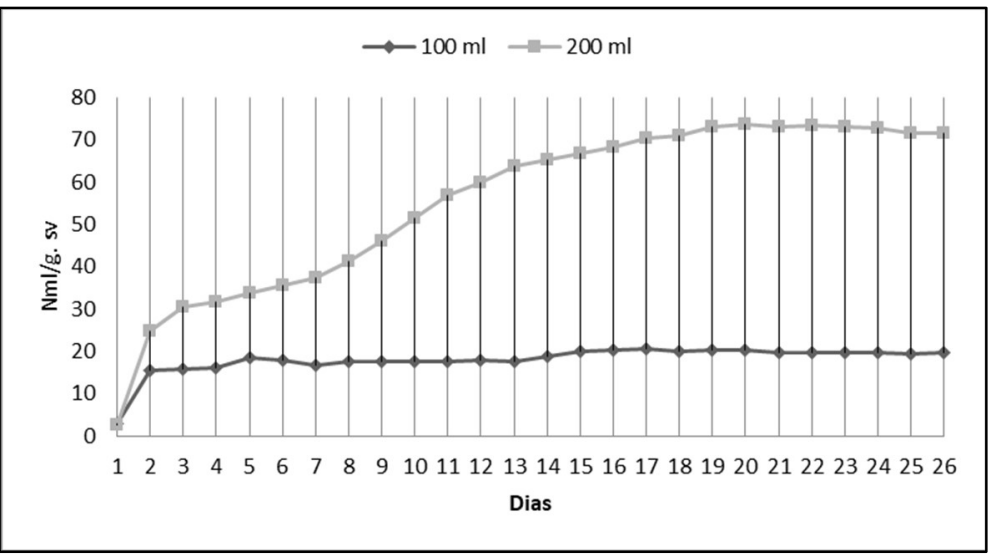

Figura 5: Geração acumulada média de biogás $(n=3)$ por grama de sólido volátil.

\section{Relações entre o pH e inóculo}

O pH configura-se como um parâmetro chave para a digestão anaeróbica, uma vez que influencia no crescimento e desempenho das bactérias presentes na comunidade microbiana, que necessitam de diferentes faixas de pH (de 4 a 8,5). Para a metanogênese, o pH ideal deve estar próximo de 7 (de 6,5 a 7,2) e se o ambiente estiver ácido, a produção de metano é interrompida (NUNES, 2012; ZHANG et al., 2014; BRASIL, 2015).

Os dois valores (de 2,03 e 5,29) se encontram abaixo do que se espera para o digerido, que deve apresentar um pH próximo de 7,5, conforme apontam Beggio et al. (2019). Os baixos valores de pH observados nos digeridos (principalmente referente a triplicata B), podem possuir explicação na alta razão de substrato por inóculo em termos de SV, o que pôde levar ao acúmulo de ácidos graxos voláteis (AGV) e, consequentemente, condições ácidas no digestor (ZHU et al., 2014). Outrossim, a diminuição do pH em experimentos com alta razão de substrato/inóculo também pode ser verificada em Brown et al. (2013) e Shi et al. (2014), que atribuem a ocorrência ao acúmulo de ácidos orgânicos e uma limitada capacidade de tamponamento, respectivamente. Zhang et al. (2014) também relatam que uma alta carga orgânica pode 
acarretar no acúmulo desses ácidos (que são os principais produtos intermediários durante a digestão), resultando na diminuição do pH.

Sob isso, destaca-se a limitada capacidade de tamponamento como uma função do inóculo, uma vez que um inóculo de qualidade tem como característica o efeito de correção do $\mathrm{pH}$ e a possibilidade de tamponar o meio (ELBESHBISHY et al., 2012). Desta maneira, quando utilizada uma quantidade relativamente baixa de inóculo tem-se a sobrecarga do processo (que resulta na acidificação), sendo o inóculo importante fator para fornecer atividade metanogênica suficiente para vencer o acúmulo de AGV, que possui sua maior produção no primeiro dia após inicializado o processo (ANGELIDAKI et al., 2004). Esta última constatação possui rebatimento no comportamento de geração de biogás da triplicata com $100 \mathrm{ml}$ (vide Figuras 3 e 4), uma vez que após o segundo dia, tal produção se manteve quase inalterada, indicando que alguma inibição ocorreu no sistema logo nos primeiros dias de experimento.

\section{CONCLUSÕES}

Verificou-se que a triplicata B (200 ml de quantidade de inóculo) apresentou um valor médio na geração de biogás (valor $p=0,028$ ) de 3,4 vezes maior que a triplicata $A$ (100 $\mathrm{ml}$ de inóculo), o que é corroborado pela redução de 13,73 \% na quantidade de sólidos voláteis, ou seja, as triplicatas B e A apresentaram redução de $66,34 \%$ e 52,61\% respectivamente. A triplicata B, com maior quantia de inóculo apresentou um comportamento de produção de biogás atrasada, decorrente da co-digestão dos resíduos alimentares e grama, que são substratos com diferentes graus de digestibilidade pelos microrganismos. Por sua vez o a triplicata $A$, com $100 \mathrm{ml}$ de inóculo, apresentou um comportamento de inibição na geração de biogás, que pode estar relacionado com o acúmulo de ácidos graxos e limitada capacidade de tamponamento. Este último possui rebatimento nos valores de $\mathrm{pH}$ observados, no qual a triplicata $\mathrm{A}$, com menor quantidade de inóculo, apresentou um pH 2,6 vezes inferior à triplicata $B$, de $200 \mathrm{ml}(\mathrm{p}$ valor $=0,000)$. Infere-se que a quantidade de $100 \mathrm{ml}$ provavelmente não foi eficiente para fornecer a quantidade de microrganismos suficientes para vencer a produção de ácidos orgânicos voláteis, que ocorre em maior quantidade após o primeiro dia de incubação. Deste modo, depreende-se que a quantidade de inóculo possui um papel fundamental na geração de biogás, que vai além do controle do pH.

\section{REFERÊNCIAS}

APHA. American Public Health Association. Standard methods for the examination of water and wastewater. 22 ed. Washington: APHA, 2012.

ANGELIDAKI, I.; BOLZONELLA, D.; ALVES, M. S.; BORZACCONI, L.. Defining the biomethane potential (BMP) of solid organic wastes and energy crops: a proposed protocol for batch assays. Water Science \& Technology, v.5, n.59, p.927-934, 2009.

ANGELIDAKI, I.; SANDERS, W.. Assessment of the anaerobic biodegradability of macropollutants. Reviews in

Environmental Science and Biotechnology, v.3, n.2, p.117129, 2004.
BEGGIO, G.; BONATO, T.; SCHIEVANO, A.; HENNEBERT, P.. Statistical analysis for the quality assessment of digestates from separately collected organic fraction of municipal solid waste (OFMSW) and agro-industrial feedstock. Should input feedstock to anaerobic digestion determine the legal status of digestate?. Waste Management, v.87, p.546-558, 2019.

BRAGUGLIA, C. M.; GIANICO, A.; GALLIPOLI, A.; PAGLIACCIA, $P$.. Anaerobic bioconversion of food waste into energy: $A$ critical review. Bioresource Technology, v.248, p.37-56, 2018.

BRASIL. Ministério das Cidades. Tecnologias de digestão 
anaeróbica com relevância para o Brasil: substratos, digestores e uso de biogás. Brasília: MC, 2015.

BROWN, D.; LI, Y.. Solid state anaerobic co-digestion of yard waste and food waste for biogas production. Bioresource Technology, v.127, p.275-280, 2013.

CHEN, X.; SHENG, K. YAN, W.; SANATI, M.. Comparison of high-solids to liquid anaerobic co-digestion of food waste and green waste. Bioresource Technology, v.154, p.215-221, 2014.

ELBESHBISHY, E.; NAKHLA, G.; HAFEZ, H.. Biochemical methane potential (BMP) of food waste and primary sludge: Influence of inoculum pre-incubation and inoculum source. Bioresource Technology, v.110, p.18-25, 2012.

GONÇALVES, C. D. C.. Modelagem do processo de digestão anaeróbica da forsu à escala industrial. Dissertação (Mestrado em Engenharia do Ambiente) - Instituto Superior Técnico, Lisboa, 2012.

HOLLIGER, C.; ALVES, M. S.; ANDRADE, D.; ANGELIDAKI, I.. Towards a standardization of biomethane potential tests. Water Science \& Technology, v.74, n.11, p.2515-2522, 2016.

KOCH, K.; LIPPERT, T.; DREWES, J. E.. The role of inoculum's origin on the methane yield of different substrates in biochemical methane potential (bmp) tests. Bioresource Technology, v.243, p.457-463, 2017.

LEITE, W.; MAZAZZIOLI, E.; GUIMARÃES, L.; MAGO, A. D.; BELLI FILHO, P.. Análise comparativa dos efeitos da carga orgânica e do tempo de detenção hidráulica na digestão anaeróbia mesofílica de lodo adensado de estação de tratamento de esgoto. Engenharia Sanitária e Ambiental, Rio de Janeiro, v.20, n.4, p.581-588, 2015.

LESTEUR, M.; MAUREL, V. B.; GONZALEZ, C.; LATRILLE, E.; ROGER, J. M.; JUNQUA, G.; STEYER, J. P.. Alternative methods for determining anaerobic biodegradability: a review. Process Biochemistry, v.45, n.4, p.431-440, 2010.

LI, Y.; XU, H.; HUA, D.; ZHAO, B.. Two-phase anaerobic digestion of lignocellulosic hydrolysate: Focusing on the acidification with different inoculum to substrate ratios and inoculum sources. Science of The Total Environment, v.699, n.134226, p.1-37, 2019.

LIMA, H. Q.. Determinação de parâmetros cinéticos do processo de digestão anaeróbia dos resíduos orgânicos de
Santo André/SP por meio de testes do potencial bioquímico de metano. Tese (Doutorado em Energia) Universidade Federal do ABC, São Paulo, 2016.

NEVES, L.; OLIVEIRA, R.; ALVES, M.. Influence of inoculum activity on the bio-methanization of a kitchen waste under different waste/inoculum ratios. Process Biochemistry, v.39, n.12, p.2019-2024, 2004.

NUNES, J. A.. Tratamento biológico de águas residuárias. 3. ed. Aracaju: J. Andrade, 2012.

OHEMENG-NTIAMOAH, J.; DATTA, T.. Perspectives on variabilities in biomethane potential test parameters and outcomes: A review of studies published between 2007 and 2018. Science of The Total Environment, v.664, p.1052 1062,2019

REIS, M. M.. Testes de diferenças entre médias. Florianópolis: UFSC, 2019.

SHI, J.; XU, F.; WANG, Z.; STIVERSON, J. A.. Effects of microbial and non-microbial factors of liquid anaerobic digestion effluent as inoculum on solid-state anaerobic digestion of corn stover. Bioresource Technology, v.157, p.188-196, 2014.

STRÖMBERG, S.; NISTOR, M.; LIU, J.. Towards eliminating systematic errors caused by the experimental conditions in Biochemical Methane Potential (BMP) tests. Waste Management J., v.34, n.11, p.1939-1948, 2014.

WALTER, A.; JUÁREZ, M. F.; D.; SILBERBERGER, S.; INSAM, H.. Biomethane potential of industrial paper wastes and investigation of the methanogenic communities involved. Biotechnology for biofuels, v.9, n.1, p.1, 2016.

YANG, L.; XU, F.; GE, X.; LI, Y.. Challenges and strategies for solid-state anaerobic digestion of lignocellulosic biomass. Renewable and Sustainable Energy Reviews, v.44, p.824$834,2015$.

ZHANG, C.; SU, H.; BAEYENS, J.; TAN, T.. Reviewing the anaerobic digestion of food waste for biogas production. Renewable and Sustainable Energy Reviews, v.38, n.11, p.383-392, 2014.

ZHU, J.; ZHENG, Y.; XU, F.; LI, Y.. Solid-state anaerobic codigestion of hay and soybean processing waste for biogas production. Bioresource technology, v.154, p.240-247, 2014.

A CBPC - Companhia Brasileira de Produção Científica (CNPJ: 11.221.422/0001-03) detém os direitos materiais desta publicação. Os direitos referem-se à publicação do trabalho em qualquer parte do mundo incluindo os direitos às renovações, expansões e disseminacões da contribuicão, bem como outros direitos subsidiários. Todos os trabalhos publicados eletronicamente poderão posteriormente ser publicados em coletâneas impressas sob coordenação da Sustenere Publishing, da Companhia Brasileira de Produção Científica e seus parceiros autorizados. Os (as) autores (as) posteriom os direitos autorais, mas não têm permissão sob coordenação da Sustenere Publishing, da Companhia Brasileira de Produção Cientifica e seus parce 